\title{
CONTROLE PREVENTIVO E CURATIVO DA FERRUGEM DO ÁLAMO EM VIVEIRO
}

\author{
Hellen Aparecida Arantes dos Santos*, Louise Larissa May de Mio** \\ * Enga . Agrônoma - hellen.arantes@ibest.com.br

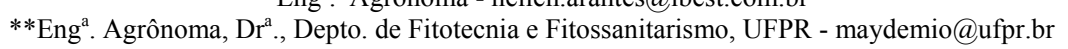 \\ Recebido para publicação: 22/09/2006 - Aceito para publicação: 04/06/2007
}

\begin{abstract}
Resumo
A ferrugem do álamo é a principal doença da cultura, tanto no campo como no viveiro, na área de plantio do Brasil. A principal causa de dano é a desfolha precoce que a doença causa. Neste trabalho, avaliou-se o efeito curativo e preventivo de controle, bem como a ação fungiostática inerente in vitro, de alguns produtos. Foram realizados dois experimentos no viveiro com o clone mais suscetível ("Latorre") delineado em quatro blocos e seis tratamentos: acibenzolar-S-methyl, amônia quaternária, mancozebe, tebuconazole + azoxistrobina e testemunha, nas safras 2003/04 e 2004/05. A avaliação da doença foi realizada de dezembro a abril, por incidência, severidade e desfolha no período. Além disso, mediu-se a altura e o diâmetro da planta à altura do peito (DAP) no final de cada experimento. In vitro, avaliou-se o potencial dos fungicidas em inibir a germinação de esporos a 1,10 e 100 g.L $\mathrm{L}^{-1}$. A mistura de azoxistrobina e tebuconazole reduziram $98,4 \%$ da germinação de urediniósporos. Os produtos à base de tebuconazole foram eficientes no controle preventivo e curativo da doença, reduzindo a desfolha em $30 \%$ e não influenciando o DAP. A desfolha foi explicada pela severidade, com coeficiente de determinação $\left(\mathrm{R}^{2}\right)$ igual a 0,69 .

Palavras-chave: Álamo; controle químico; Melampsora medusae.
\end{abstract}

\section{Abstract}

Preventive and curative control of poplar rust in nursery. The poplar rust is the main disease in the field and nursery conditions in poplar area in Brazil. The main damage caused by this disease is the early defoliation. In this work was assessed curative and preventive control in the field and also the inhibitory effect to the spores germination of some fungicides in vitro. Two experiments were carried out in poplar nursery using the most susceptible clone ("Latorre") using four blocs and six treatments: acibenzolar-S-methyl, quaternary ammonium, mancozeb, tebuconazole + azoxystrobin and control, during 2003/04 e 2004/05. The disease assessment was from December to April by incidence, severity and defoliation. Also was assessed the height and diameter of breast height (DBH) on the end of the experiment. In vitro was considered potencial to reduce spores germination at 1,10 e 10 g.L. $\mathrm{L}^{-1}$. The mixture of azostrobina and tebuconazole reduced 98,4 \% of uredospores germination. The products with tebuconazole were efficient to preventive and curative control of the disease and also reduced the defoliation on $30 \%$ but no influence was observed on the DBH. The defoliation was explained by the disease severity with 0,69 of determinant coefficient $\left(\mathrm{R}^{2}\right)$.

Keywords: Poplar; chemical control; Melampsora medusae.

\section{INTRODUÇÃO}

No vale do rio Iguaçu, estado do Paraná, vários híbridos de álamo (Populus spp) são utilizados para produção de madeira, principalmente por indústrias de palitos de fósforo. A maioria do material genético inclui a espécie Populus deltoides Bartr. ex. Marsh. suscetível à ferrugem das folhas (Melampsora medusae Thuem.) (SPIERS, 1975; MCCRACKEN et al., 1984; NEWCOMBE; CHASTAGNER, 1993). No Brasil, o primeiro relato foi em 1945, em São Paulo (VIÉGAS, 1945) e em 1968 no Paraná (NOWACKI; FONTOURA, 1968). Os sintomas são pústulas diminutas de coloração amarela a alaranjada em ambas as superfícies foliares. Quando as pústulas coalescem, são formadas regiões necrosadas, levando à queda prematura das folhas.

A ferrugem do álamo pode ser causada por diferentes espécies do gênero Melampsora, como $M$. larici-populina Kleb., M. allii-populina Kleb. e M. medusae, entre outras. A ferrugem causada por $M$. 
medusae é macrocíclica e heteróica, ocorrendo também em espécies de Larix na América do Norte (WALKER, 1975). Ainda não há relatos de ocorrência de $M$. medusae no hospedeiro alternativo no Brasil. É possível que, em plantações brasileiras, a sobrevivência do patógeno ocorra pela continuidade de ciclos secundários no próprio álamo, pois, apesar do hábito caducifólio, algumas plantas mantêm as folhas por praticamente todo o ano (MAY DE MIO, 2001). Esta forma de sobrevivência já foi reportada em países de clima temperado, quando da ocorrência de invernos amenos (CHASTAGNER, 2001).

A desfolha prematura causada por M. medusae provoca redução de 30 \% (MAY DE MIO et al., 2002) a 65\% no volume da planta no viveiro (WIDIN; SCHIPPER, 1976; STEENACHERS et al., 1995). Trabalhos na França têm relacionado o efeito do ataque da espécie M. larici-populina com a qualidade de madeira, mostrando que a desfolha provocada por uma epidemia severa reduz o crescimento da planta no ano seguinte e, em conseqüência, o cerne não se forma completamente (STEENACHERS et al., 1995).

$\mathrm{O}$ controle da doença por meio da pulverização de fungicidas, tanto no viveiro quanto na plantação, embora eficiente (GIORCELLI; VIETTO, 1995; PANDEY et al., 1996), não é a medida usual de controle nos grandes países produtores. O controle químico tem sido feito muitas vezes por pulverizações aéreas de triazóis, o que gera um alto custo e agressão ao meio ambiente, pois a maioria das plantações está localizada em áreas de várzeas próximas ao rio Iguaçu. O plantio de clones resistentes à ferrugem é a medida de controle adotada por vários países produtores de álamo, embora seu uso seja prejudicado em virtude da alta variabilidade do patógeno (MOLTZAN, 1991; NEWCOMBE et al., 1996). As pesquisas de resistência a doenças são incipientes e o manejo da epidemia ainda precisa de ajustes, pois na região há uma utilização direcionada para fungicidas do grupo dos triazóis. Esses produtos são excelentes para o controle, entretanto, se não for seguida a alternância com outros grupos, há o risco do desenvolvimento de resistência do patógeno a esse grupo químico. Os triazóis e imidazóis inibem a biossíntese de ergosterol, substância que se acumula na membrana celular, conferindo-lhe estrutura e seletividade (FORCELINI, 1994). Para solucionar esse problema, são citados na literatura produtos de contato, como o mancozebe, e produtos de outros grupos, como o caso das estrobirulinas (MAY DE MIO, 2001).

A utilização de fungicidas dos grupos dos triazóis e das estrobirulinas é uma prática que ocorre em diversas culturas, no tratamento de várias espécies de ferrugens, como na Phakopsora pachyrhizi, em que foi avaliado o efeito protetor, curativo e erradicante de fungicidas sistêmicos em plantas de soja (Glycine max) inoculadas com suspensão de urediniósporos de P. pachyrhizi, em casa de vegetação (GODOY; CANTERI, 2004).

Para a cultura do álamo, o uso de fungicidas é limitado, devido à dificuldade de registro para a cultura, considerando sua expressão econômica para o estado e para o país. Além disso, o controle químico não é $100 \%$ efetivo ao longo do tempo, pois as populações patogênicas possuem caráter mutagênico, desenvolvendo resistência, além da grande variabilidade genética. Quanto ao risco de desenvolvimento de resistência, sabe-se que as dicarboximidas são consideradas de risco alto, os inibidores da biossíntese de esteróis, anilinopirimidinas e estrobilurinas são de médio risco e os ditiocarbamatos são de baixo risco (GHINI; KIMATI, 2002). Por isso, para o manejo adequado, é necessária a busca constante por produtos de diferentes origens e grupos químicos, avaliando-se a ação curativa e preventiva no campo.

Para avaliar a eficiência de medidas de controle à ferrugem, é importante quantificar não apenas as variáveis relacionadas à intensidade da doença, como a severidade, mas também a desfolha. A queda de folhas em decorrência da elevada severidade faz com que a intensidade da doença seja subestimada ao final do ciclo da cultura, pois as folhas remanescentes na árvore apresentam severidade mais baixa que as já caídas (MAY DE MIO et al., 2006). Outro fator importante é conhecer quanto a epidemia e a desfolha podem causar de prejuízo na planta em termos de crescimento.

Com este trabalho, objetivou-se verificar a eficiência de controle preventivo e curativo de produtos químicos (amônia quaternária, tebuconazole e azoxistrobina) e indutor de resistência (acibenzolar-S-methyl), por meio de relações entre incidência, severidade e parâmetros de crescimento da planta. Além disso, avaliou-se a porcentagem de germinação dos urediniósporos in vitro em relação aos produtos químicos utilizados. 


\section{MATERIAIS E MÉTODOS}

\section{Avaliação da inibição da germinação de urediniósporos in vitro}

Foi conduzido, sob condições assépticas no Laboratório de Fitopatologia do Departamento de Fitotecnia e Fitossanitarismo do Setor de Ciências Agrárias da Universidade Federal do Paraná, um teste in vitro para comparar a porcentagem de germinação de esporos em diferentes fungicidas, nas concentrações 1,10 e 100 g.L $L^{-1}$ de ingrediente ativo em meio de cultura.

Para a execução desse ensaio, foi utilizada uma suspensão de $10^{5}$ urediniósporos de Melampsora medusae/mL, sendo os urediniósporos obtidos de folhas de álamo com sintomas de ferrugem provenientes do campo experimental da região de São Mateus do Sul. Uma alíquota de $0,1 \mathrm{~mL}$ dessa suspensão foi adicionada a placas de Petri com AA (Ágar + Água) contendo solução desses fungicidas, tebuconazole (200 g.L $\mathrm{L}^{-1}$ de ingrediente ativo), azoxistrobina (250 g.L. $\mathrm{L}^{-1}$ de i.a.) e mancozebe (200 g.. ${ }^{-1}$ de i.a.) a 1,10 e 100 g. $\mathrm{L}^{-1}$. Após devidamente identificadas, essas placas foram mantidas em estufa a $21^{\circ} \mathrm{C}$ por 24 horas na ausência de luz, para que o urediniósporo iniciasse o processo de germinação. Após esse período, foram depositadas quatro gotas de Azul de Amman + Lactofenol em cada placa de Petri, com a finalidade de paralisar a germinação dos urediniósporos e colorir os tubos germinativos. A avaliação da germinação foi realizada por meio da contagem de 100 urediniósporos por placa, utilizando microscópio óptico. Foram considerados germinados os urediniósporos que apresentaram tubo germinativo de comprimento igual ou maior ao comprimento do urediniósporo. A partir dos dados, foi estabelecido o percentual de urediniósporos germinados por repetição, em cada um dos tratamentos.

Como parâmetro estatístico utilizou-se o delineamento inteiramente casualizado (DIC), com quatro tratamentos, em cinco repetições, sendo cada placa de Petri uma repetição. O teste de significância utilizado foi o Scott-Knott a 5\%.

\section{Controle preventivo da ferrugem em viveiro}

$\mathrm{O}$ efeito protetor ou preventivo refere-se à proteção da planta conferida pela aplicação do produto antes da deposição do patógeno. Essa etapa foi realizada na Fazenda Santa Teresa, em Canoinhas/SC, na safra de 2004/2005. Os tratamentos foram iniciados em 20 de novembro de 2004, antes do aparecimento dos sintomas.

Foi utilizado o delineamento em blocos ao acaso. Cada bloco foi dividido em seis parcelas, cada uma delas de 2,5 x $20 \mathrm{~m}$, sendo a área total do experimento de 0,12 ha, no viveiro dos clones de Latorre com 1 ano de idade. Em cada parcela foram marcadas dez plantas, com fitas de tecido TNT (tecido não tecido), a $1,70 \mathrm{~m}$ de altura. As pulverizações foram realizadas através de canhões pulverizadores, tratorizados, com vazão de $200 \mathrm{~L}$.ha ${ }^{-1}$. Foram testados seis tratamentos: acibenzolar-S-methyl, $\left(500{\mathrm{~g} . \mathrm{kg}^{-1}}^{-1}\right.$ de ingrediente ativo), cloreto de benzalcônio (100 g. $\mathrm{L}^{-1}$ de i.a.), um produto de contato à base de mancozebe (200 g. $\mathrm{L}^{-1}$ de i.a.) e dois produtos sistêmicos, uma estrobilurina à base de azoxistrobina (200 g. $\mathrm{L}^{-1}$ de i.a. $)$ e um triazol à base de tebuconazole $\left(200 \mathrm{~g} . \mathrm{L}^{-1}\right.$ de i.a. $)$.

Após vinte dias da instalação do experimento, iniciaram-se as avaliações. Para quantificar a doença, foram avaliadas a incidência (contando-se o número total de folhas e folhas com ferrugem do solo à altura da marcação) e a severidade (coletando-se vinte folhas ao acaso por parcela e determinandose o número de pústulas em $2 \mathrm{~cm}^{2}$ do limbo foliar). Foi avaliada a desfolha, contando-se o número de folhas presentes em cada planta marcada (à altura de 1,70 m) no início, durante e no final das avaliações. Essas avaliações foram realizadas a cada vinte dias. Como parâmetros para acompanhar o desenvolvimento da planta, foram avaliados a altura e o diâmetro à altura do peito (DAP).

\section{Controle curativo da ferrugem em viveiro}

O efeito curativo é aquele em que ocorre atenuação dos sintomas ou reparação dos danos provocados pelo patógeno, sendo uma ação dirigida contra o patógeno, após o estabelecimento de seu contato efetivo com o hospedeiro. O experimento foi realizado na Fazenda São Joaquim, em São Mateus do Sul (PR), no período de 2003/2004. Os tratamentos iniciaram em 15 de dezembro de 2003, após o aparecimento dos sintomas.

Foram testados seis tratamentos, os mesmos citados no item anterior, em delineamento em blocos ao acaso, sendo a área total do experimento de 0,476 ha, no viveiro dos clones de Latorre com 1 ano e meio de idade. Como parâmetro estatístico foi utilizado o teste de Scott-Knott a 5\% de 
significância. Cada bloco foi dividido em seis parcelas, sendo cada uma delas de 3,6 x $33 \mathrm{~m}$. Em cada parcela foram marcadas dez plantas a $1,70 \mathrm{~m}$ de altura. As pulverizações foram realizadas durante os meses de dezembro de 2003 a março de 2004, em intervalos de 20 dias.

No início do experimento com controle curativo, foi realizada uma avaliação da doença por bloco, determinando-se a porcentagem de incidência e a severidade da doença em uma amostra de 100 folhas/bloco, com a finalidade de verificar a uniformidade do inóculo entre os blocos. As demais avaliações foram feitas da mesma forma descrita no item anterior.

\section{RESULTADOS E DISCUSSÃO}

\section{Avaliação in vitro da eficiência de fungicidas}

Os fungicidas à base de tebuconazole e de mancozebe induziram índices de germinação maiores na concentração de $1 \mathrm{mg} . \mathrm{L}^{-1}$ que nas soluções de $10 \mathrm{mg} \cdot \mathrm{L}^{-1}$ e de $100 \mathrm{mg} \cdot \mathrm{L}^{-1}$. Já a associação de azoxistrobina com tebuconazole, a $1 \mathrm{mg} . \mathrm{L}^{-1}$, foi o melhor tratamento, reduzindo em $98,4 \%$ a germinação de urediniósporos. A $100 \mathrm{mg} . \mathrm{L}^{-1}$, tebuconazole reduziu $99,2 \%$ da germinação, enquanto o mancozebe apresentou resultados semelhantes nas soluções a $100 \mathrm{mg} . \mathrm{L}^{-1}$ e a $10 \mathrm{mg} \cdot \mathrm{L}^{-1}$, inibindo aproximadamente $98,4 \%$ da germinação. A $1 \mathrm{mg} . \mathrm{L}^{-1}$ foi possível observar diferenças entre os tratamentos, sendo que na associação azoxistrobina + tebuconazole o fungo obteve taxa de germinação inferior a $2 \%$. Agindo só com tebuconazole, germinou entre 5 e $10 \%$, e com mancozebe, acima de $10 \%$, como pode ser observado na figura 1.

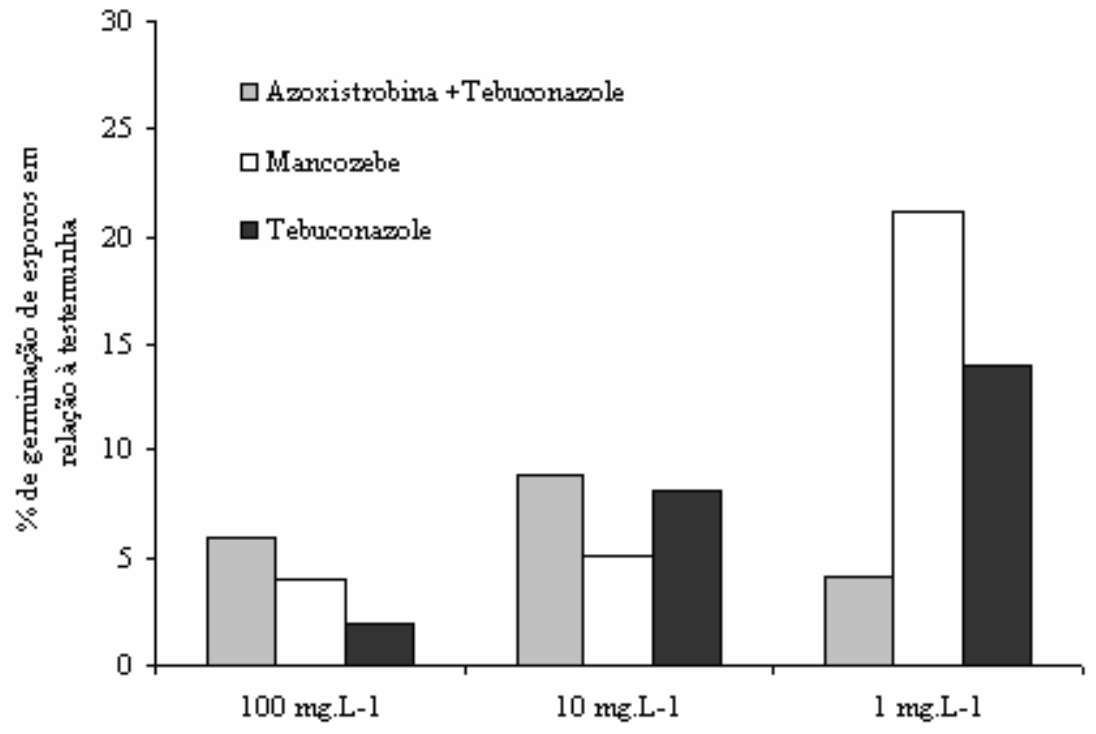

Figura 1. Porcentagem de germinação de urediniósporos de Melampsora medusae de álamo (Populus spp) em meio ágar-ágar contendo $100 \mathrm{mg} . \mathrm{L}^{-1}, 10 \mathrm{mg} . \mathrm{L}^{-1}$ e $1 \mathrm{mg} . \mathrm{L}^{-1}$ de tebuconazole, mancozebe e azoxistrobina + tebuconazole. Laboratório de Fitopatologia, UFPR, 2004.

Figure 1. Percentage of urediniospores germination of Melampsora medusae of poplar (Populus spp) in agar-water medium with $100 \mathrm{mg} . \mathrm{L}^{-1}, 10 \mathrm{mg} . \mathrm{L}^{-1}$ and $1 \mathrm{mg} . \mathrm{L}^{-1}$ of tebuconazole, mancozeb and azoxistrobina + tebuconazole. Laboratory of plant pathology, UFPR, 2004.

\section{Controle preventivo da ferrugem no viveiro}

A figura 2 mostra o comportamento da ferrugem - em incidência (Figura 2A) e severidade (Figura 2B) - em plantas de álamo tratadas preventivamente com diferentes produtos ao longo do tempo.

A epidemia nesse ciclo não foi severa, com índices de incidência variando entre 40 e $60 \%$ no final da epidemia. Em relação à incidência, por ser baixa, não foi possível diferenciar os tratamentos, 
(acibenzolar-S-methyl, amônio quartenário e mancozebe) da testemunha, pois não havia diferença estatística entre eles (Tabela 1). Os resultados foram semelhantes aos de Rocha et. al. (2000), que concluíram que a utilização de maiores concentrações do produto acibenzolar-S-methyl pode resultar em efeito significativo, ou utilizar o produto em mistura. Como exemplo, Töfoli et. al. (2005) obtiveram os maiores aumentos relativos de produtividade para as misturas de acibenzolar-S-methyl com mancozebe e com chlorothalonil. Em relação à severidade, os tratamentos com produtos do grupo dos triazóis e estrobirulina (tebuconazole $\mathrm{e}$ azoxistrobina) controlaram a doença, retardando o início da epidemia (Figura 2B). Azevedo (2003) comentou que azoxistrobina é efetivo contra patógenos que desenvolveram uma sensibilidade reduzida para outros fungicidas, podendo ser uma boa opção para o manejo com triazóis.
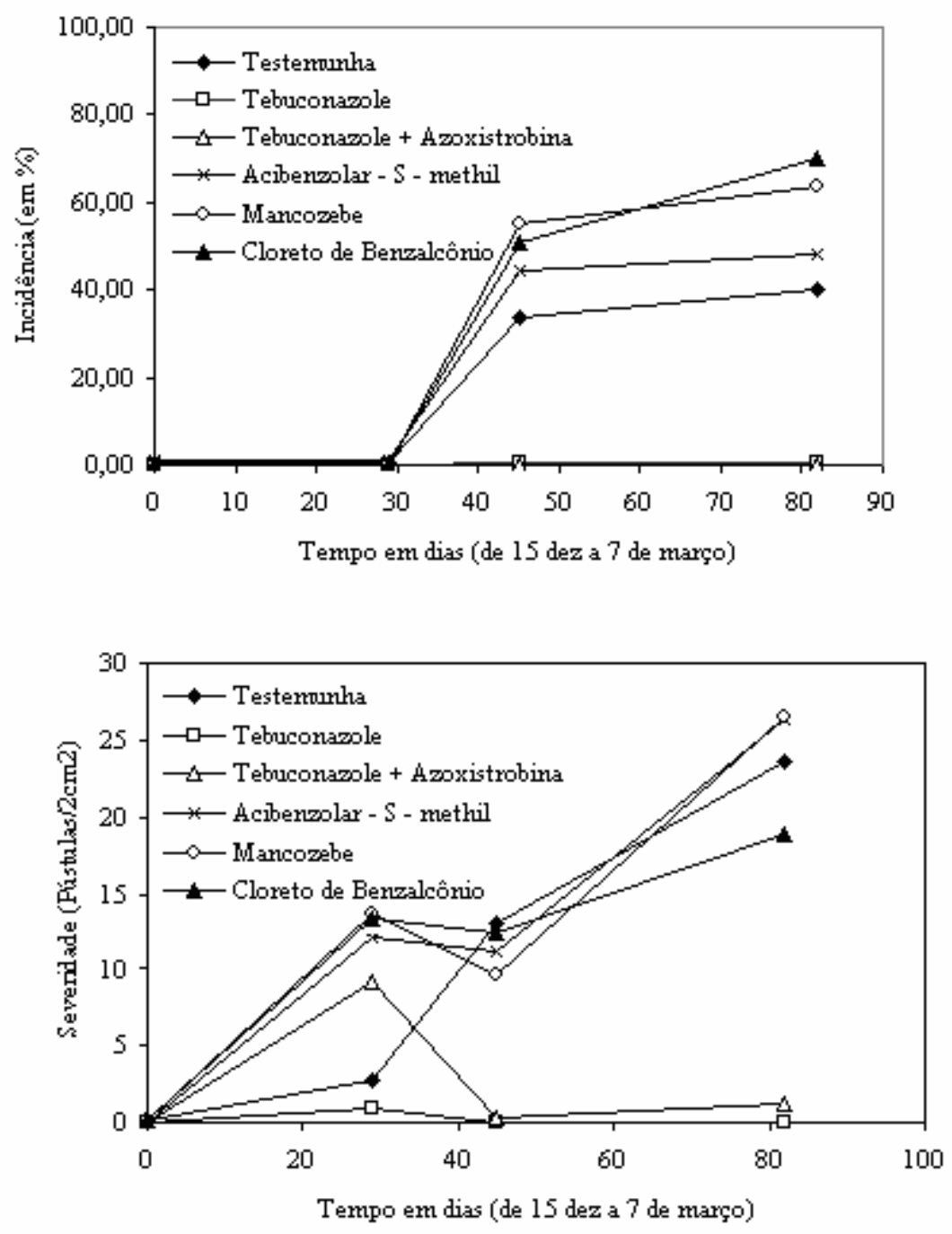

Figura 2. Curva do progresso da ferrugem em folhas de álamo (Melampsora medusae) em incidência (A) e severidade (B), de dezembro de 2004 a março de 2005, em diferentes tratamentos comparados com testemunha sem controle. Fazenda Santa Teresa, Canoinhas (SC). Safra 2004/05.

Figure 2. Poplar rust (Melampsora medusae) progress curve in incidence (A) and severity (B) from December/ 2004 to March/ 2005 in different treatments compared with the control. Santa Teresa Farm, Canoinhas (SC). Harvest 2004/05. 
Tabela 1. Incidência (\%), severidade (em pústulas $\left./ \mathrm{cm}^{2}\right)$, diâmetro à altura do peito (DAP) e altura de árvores de álamo em viveiro, tratadas de dezembro a março com diferentes produtos, em controle preventivo. Fazenda Santa Teresa, Canoinhas (SC). Safra 2004/05.

Table 1. Incidence (\%), severity (pustules $/ \mathrm{cm}^{2}$ ), diameter at breast height (DBH) and height of trees of poplar in nursery treat from December to March with different products in preventive control. Santa Teresa Farm, Canoinhas (SC). Harvest 2004/05.

\begin{tabular}{|c|c|c|c|c|}
\hline Tratamentos & $\begin{array}{l}\text { Incidência } \\
\text { 29/jan }\end{array}$ & $\begin{array}{l}\text { Severidade } \\
7 / \mathrm{mar}\end{array}$ & $\begin{array}{l}\text { DAP* } \\
(\mathbf{c m})\end{array}$ & $\begin{array}{c}\text { Altura* } \\
\text { (m) }\end{array}$ \\
\hline Testemunha & $40,0 \mathrm{a}^{* *}$ & $4,7 \mathrm{a}$ & $3,1 \mathrm{~ns}$ & $5,0 \mathrm{~ns}$ \\
\hline Tebuconazole & $0,5 \mathrm{~b}$ & $1,0 \mathrm{~b}$ & 2,9 & 5,0 \\
\hline Tebuconazole + Azoxistrobina & $0,0 \quad \mathrm{~b}$ & $1,4 \mathrm{~b}$ & 3,0 & 4,8 \\
\hline Acibenzolar-S-methyl & $48,0 \mathrm{a}$ & $5,2 \mathrm{a}$ & 2,6 & 4,4 \\
\hline Mancozebe & $63,0 \mathrm{a}$ & $4,9 \mathrm{a}$ & 2,6 & 4,5 \\
\hline Amônio quartenário & $70,0 \mathrm{a}$ & $4,3 \mathrm{a}$ & 2,7 & 4,7 \\
\hline Coef. Variação (\%) & 50 & 32,6 & 8,2 & 8,6 \\
\hline
\end{tabular}

*Ao final das avaliações em março; **teste de Scott-Knott a 5\% de significância; ns: não significativo pela análise de variância.

Os melhores tratamentos foram os fungicidas tebuconazole e azoxistrobina, que não passaram de 7 pústulas $/ 2 \mathrm{~cm}^{2}$, enquanto a severidade no final da epidemia alcançava cerca de 25 pústulas. Esses valores são baixos para essa fase da cultura (início de março), pois, provavelmente por ser área nova, ainda estava com baixo potencial de inóculo. Em trabalhos anteriores, May de Mio (2001) relatou severidade de 350 pústulas $/ \mathrm{cm}^{2}$, sendo estas responsáveis por desfolhas prematuras em diferentes clones. O resultado da epidemia foi pouco agressivo nessa fase, sendo evidenciado no desenvolvimento da planta (DAP e altura), que se manteve sem diferenças estatísticas entre os tratamentos (Tabela 1).

Em relação à desfolha, não foram observadas diferenças neste experimento (dados não apresentados). Para conhecer o efeito dos produtos nessa variável, recomenda-se uma avaliação em anos consecutivos, em condições de epidemia mais severa e com controle preventivo. Também seria interessante avaliar os produtos alternativos aos químicos convencionais em outras dosagens, no caso dos produtos que não foram eficientes. É fundamental a pesquisa de novas alternativas de produtos para manejo de fungicidas na área, evitando assim a resistência do fungo aos produtos já eficientes. Fungicidas com modo de ação específico possuem um maior risco de seleção de populações resistentes do patógeno, devendo-se, dessa forma, alternar produtos com diferentes modos de ação ou utilizar misturas prontas dos dois grupos (KIMATI, 1995; MAY DE MIO et al., 2000).

\section{Controle curativo}

A avaliação prévia do inóculo presente na área mostrou uma uniformidade entre as parcelas em relação à incidência e severidade da ferrugem. Como podem ser observadas na figura 3, todas as parcelas estavam com incidência e severidade relativamente altas, variando em torno dos $100 \%$ em incidência e com severidade de 25-40 pústulas $/ 2 \mathrm{~cm}^{2}$. Segundo Martinelli (1994), severidade de apenas $5 \%$ ou incidência de 15-20\% (REIS, 1998) de ferrugem asiática já representam reduções na produtividade de grãos, por unidade de área, iguais ao custo do tratamento químico.

Após duas pulverizações com os tratamentos à base de tebuconazole e tebuconazole + azoxistrobina, ocorreu uma redução na doença tanto em incidência como em severidade, sendo a incidência menor para tebuconazole. Para a severidade, os tratamentos tiveram comportamento semelhante na avaliação de início de janeiro (Tabela 2). Para Amorim (1995), o parâmetro incidência (porcentagem de infecção da moléstia na lavoura, considerando plantas individuais) é de maior simplicidade e precisão, além de fornecer uma idéia clara da intensidade da doença, sem nenhuma subjetividade, pois avalia apenas a presença ou ausência de pústulas. Entretanto, segundo a mesma autora, a severidade é o parâmetro mais apropriado para doenças foliares, como as ferrugens e oídio. Neste experimento, a epidemia foi extremamente severa, e nestas avaliações foram consideradas apenas pústulas com esporulação (avaliação curativa), pois as lesões iniciais continuavam na folha, mas nos referidos tratamentos eficientes elas não estavam mais ativas. 


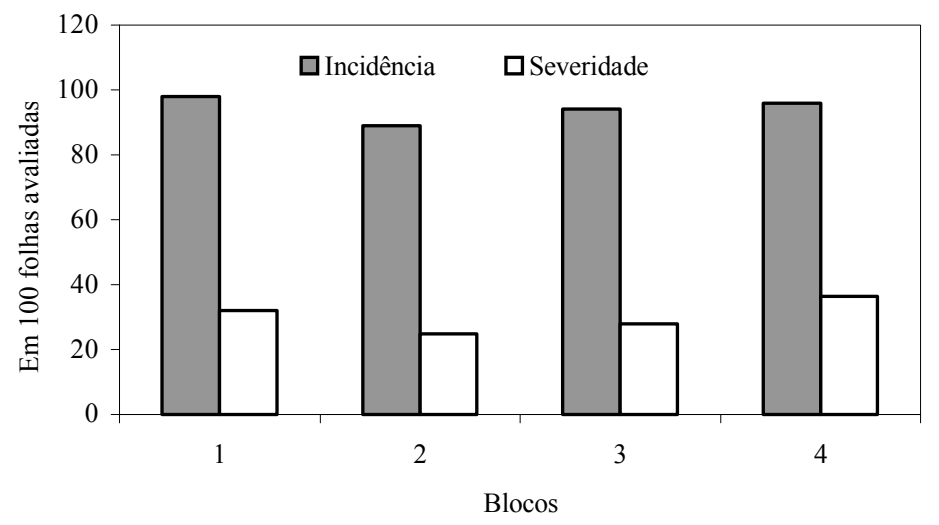

Figura 3. Incidência (\%) de ferrugem em folhas e severidade avaliada em número de pústulas $/ 2 \mathrm{~cm} 2 \mathrm{de}$ limbo foliar, antes da instalação do experimento, realizada em 15/12/2003. Fazenda São Joaquim, São Mateus do Sul (PR).

Figure 3. Incidence (\%) of rust in leaves and severity evaluated in number of pustules $/ 2 \mathrm{~cm}^{2}$ of foliar limb before installation of experiment, done in 15/12/2003. São Joaquim Farm, São Mateus do $\mathrm{Sul}(\mathrm{PR})$

Neste estudo verificou-se que os tratamentos podem ter provocado um pequeno efeito de fitotoxicidade, evidenciado pela altura das plantas, pois elas estavam estatisticamente menores nas parcelas tratadas comparadas com a testemunha. Entretanto, esse efeito pode ser uma resposta à desfolha precoce que ocorreu com a testemunha, pois, em relação ao DAP, não foi observada diferença (Tabela 2). A desfolha foi evidente na testemunha 22 dias após o início do experimento, chegando a quase $100 \%$ aos 41 dias. Resultados obtidos por Andrade e Andrade (2002), no controle químico da ferrugem asiática, mostraram que um atraso de sete dias na aplicação do fungicida (após a detecção da doença) já foi suficiente para um aumento na desfolha de $82 \%$, em relação às parcelas submetidas ao tratamento fungicida efetuado quando do aparecimento da doença. Quando esse atraso no início da pulverização foi de 14 dias, a desfolha aumentou em 155\%. Nessa fase, os melhores tratamentos, com efeito positivo, impedindo a desfolha, foram tebuconazole, tebuconazole + azoxistrobina e amônio quartenário. Soares et. al. (2004), estudando o efeito de fungicidas no controle da ferrugem asiática, obtiveram índices satisfatórios de controle com uso de fungicidas à base de tebuconazole e à base de azoxistrobina. No início da epidemia, todos os produtos retardaram a desfolha em relação à testemunha.

No inicio do experimento, em 15 de dezembro, a incidência estava alta na testemunha e no tebuconazole (97,7 e 94,2\% respectivamente). Durante o período de avaliações, observou-se que mancozebe, acibenzolar-S-methyl e a testemunha obtiveram 100\% de incidência, em 7 de janeiro, seguidos pelo cloreto de benzalcônio. Para Novartis (1997), a aplicação de produto químico com a finalidade de induzir resistência deve ser feita preventivamente, para que os mecanismos de defesa da planta sejam estimulados. Segundo Forcelini (2003), os fungicidas têm sua eficácia muito reduzida quando aplicados após o estabelecimento da ferrugem. Já a mistura de tebuconazole e azoxistrobina demonstrou um decréscimo de $26 \%$. Além do efeito protetor, os sistêmicos são também curativos e erradicantes, permitindo, em alguns casos, a sua aplicação com índices de ferrugem mais elevados (MATIELLO et al., 1995; BARBOSA et al., 1998). Entretanto o tebuconazole, que no início das avaliações apresentava $94,2 \%$ de incidência, decresceu para $0,5 \%$ ao término das avaliações. Segundo Godoy e Canteri (2004), os tratamentos com triazóis, estrobilurina e mistura dos dois princípios ativos apresentaram controle superior a $90 \%$.

Outro aspecto a considerar é a relação entre a severidade e a desfolha e também entre a incidência e a severidade. A figura 4 mostra que houve correlação entre desfolha e severidade, sendo que se esta foi responsável por aproximadamente $70 \%$ da desfolha, os outros $30 \%$ foram devidos a outras causas, tais como desfolha natural e clima, dentre outros fatores desconhecidos. De acordo com Campbell e Madden (1990), quando se faz o monitoramento das variáveis meteorológicas, é possível identificar períodos de condições favoráveis às doenças, permitindo o estabelecimento dos momentos mais 
apropriados às aplicações de fungicidas. Dessa maneira, podem-se obter informações sobre quando as pulverizações devem ser iniciadas e o intervalo que elas devem ser feitas, ou, ainda, se devem ser feitas com a mesma freqüência em todas as épocas do ciclo. A figura 4A mostra que, conforme aumenta a severidade na parcela, aumenta também a desfolha, e na figura 4B verifica-se que existe relação entre a incidência e a severidade. Entretanto, a severidade ainda é um parâmetro mais preciso e confiável para relacionar com a desfolha, pois os dados de incidência não correlacionam positivamente com desfolha (dados não apresentados). Não foi observada correlação entre severidade ou desfolha com valores de DAP e altura da planta dentro do mesmo ano de experimento. Dados concordantes foram obtidos por May de Mio et. al. (2006) em experimento avaliando dano por ferrugem no campo.
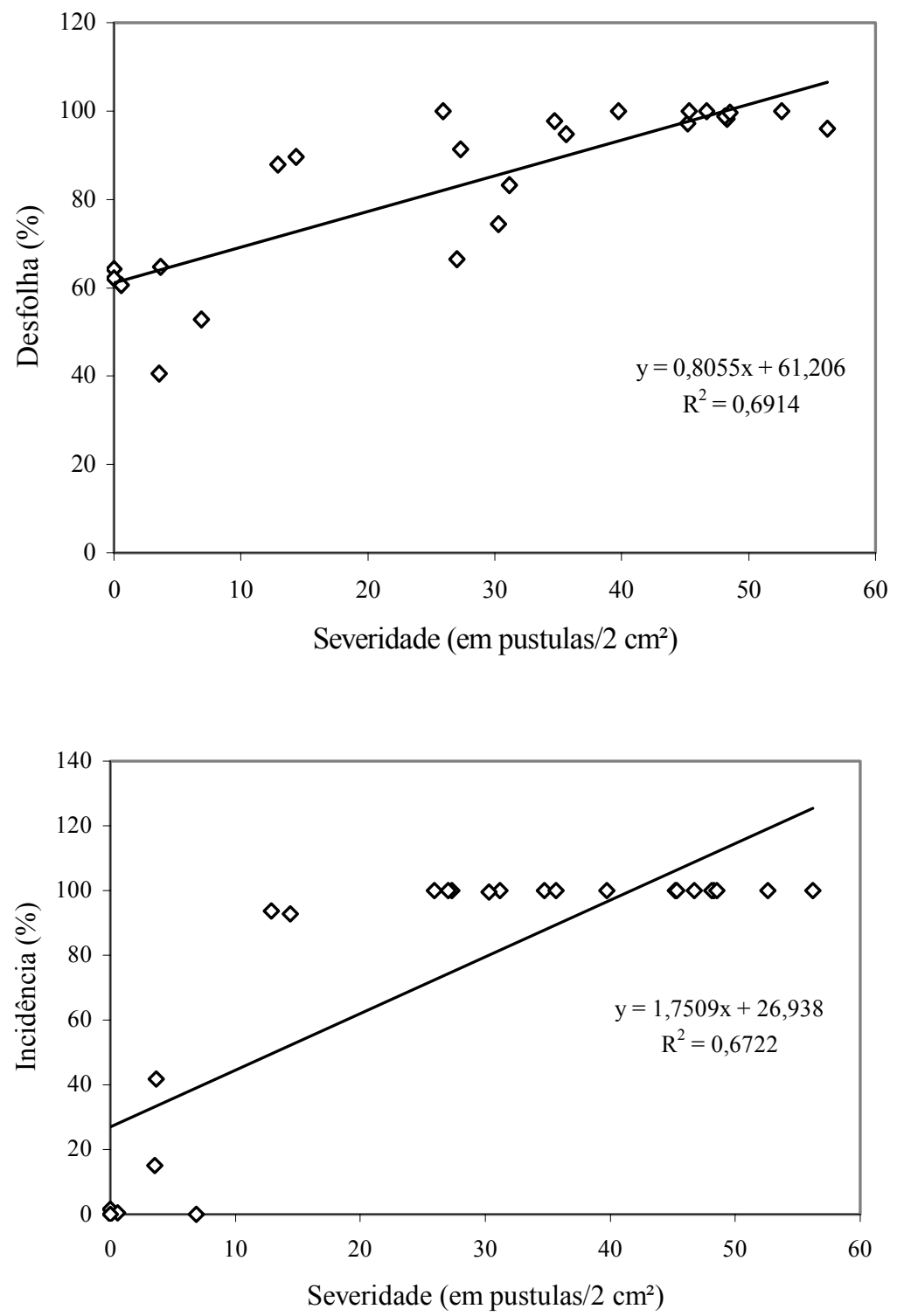

Figura 4. Relação entre severidade e desfolha (A) e entre severidade e incidência (B) da ferrugem do álamo em experimento com controle curativo do patógeno. Fazenda São Joaquim, São Mateus do Sul (PR). Safra 2003/04.

Figure 4 - Relation between severity and takes away the leaves (a) and between severity and incidence (b) of the rust of the poplar in experiment with control dressing of the pathogen. São Joaquim Farm, São Mateus do Sul (PR). Harvest 2003/04. 
A figura 4 mostra a relação entre a severidade e a desfolha no experimento para controle curativo, evidenciando que quanto maior a severidade maior a desfolha $\left(\mathrm{R}^{2}=0,69\right)$, concordando com May de Mio (2001).

Tabela 2. Incidência (\%), severidade (em pústulas $\left./ \mathrm{cm}^{2}\right)$, desfolha (\%), diâmetro à altura do peito (DAP) e altura de árvores de álamo em viveiro tratadas de dezembro a março com diferentes produtos em controle curativo. Fazenda São Joaquim, São Mateus do Sul (PR). Safra 2003/04.

Table 2. Incidence (\%), severity (pustules $\left./ \mathrm{cm}^{2}\right)$, defoliation (\%), diameter at breast height (DBH) and height of trees of poplar in nursery treat from December the March with different products in curative control. São Joaquim Farm, São Mateus do Sul (PR) Harvest, 2003/04.

\begin{tabular}{|c|c|c|c|c|c|c|c|c|}
\hline \multirow{2}{*}{ Tratamentos } & \multicolumn{2}{|c|}{ Incidência (\%) } & \multirow{2}{*}{$\begin{array}{c}\text { Severidade } \\
07 / 01 \\
\end{array}$} & \multirow{2}{*}{$\begin{array}{c}\text { Altura } \\
(\mathrm{m})\end{array}$} & \multirow{2}{*}{$\begin{array}{l}\text { DAP } \\
(\mathbf{c m}) \\
\end{array}$} & \multicolumn{3}{|c|}{ Porcentagem de desfolha aos } \\
\hline & $15 / 12$ & $07 / 01$ & & & & 22 dias & 41 dias & 63 dias* \\
\hline Testemunha & $97,8 \mathrm{~ns}$ & $100,0 \mathrm{a}$ & $49,8 \mathrm{a}$ & $4,7 \mathrm{a}$ & $8,2 \mathrm{~ns}$ & $51,2 \mathrm{a}$ & $98,3 \mathrm{a}$ & 99,4 a \\
\hline Tebuconazole & 94,2 & 0,6 c & $1,9 \mathrm{c}$ & $4,0 \mathrm{~b}$ & 8,4 & $21,1 \mathrm{~b}$ & $60,0 \mathrm{~b}$ & $71,1 \mathrm{~b}$ \\
\hline $\begin{array}{l}\text { Tebuconazole + } \\
\text { azoxistrobina }\end{array}$ & 86,9 & $60,9 \mathrm{~b}$ & $8,6 \mathrm{c}$ & $3,9 \mathrm{~b}$ & 7,9 & $15,7 \mathrm{~b}$ & $70,7 \mathrm{~b}$ & $77,3 \mathrm{~b}$ \\
\hline Mancozebe & 87,8 & $100,0 \mathrm{a}$ & 47,9 a & $3,8 \mathrm{~b}$ & 7,1 & $30,2 \mathrm{~b}$ & $99,1 \mathrm{a}$ & $100,0 \mathrm{a}$ \\
\hline Acibenzolar-S-methyl & 91,7 & $100,0 \mathrm{a}$ & $31,9 \mathrm{~b}$ & $4,1 \mathrm{~b}$ & 8,3 & $21,4 \mathrm{~b}$ & $97,3 \mathrm{a}$ & $99,6 \mathrm{a}$ \\
\hline Amônio quartenário & 91,6 & 99,9 a & $31,0 \mathrm{~b}$ & $4,4 \mathrm{a}$ & 7,6 & $14,5 \mathrm{~b}$ & $79,7 \mathrm{~b}$ & $91,3 \mathrm{a}$ \\
\hline Coef. Variação (\%) & 5,24 & 20,70 & 16,5 & 8,16 & 9,89 & 43,4 & 13,1 & 11,4 \\
\hline
\end{tabular}
início da avaliação $(15 / 12 / 2003)$.

\section{CONCLUSÃO}

No teste in vitro, a germinação foi inibida aproximadamente em $100 \%$ a 10 e $100 \mathrm{mg} . \mathrm{L}^{-1}$ para todos os fungicidas testados (tebuconazole, tebuconazole + azoxistrobina e mancozebe). A 1 mg. $\mathrm{L}^{-1} \mathrm{o}$ melhor resultado foi tebuconazole + azoxistrobina.

Os produtos tebuconazole e azoxistrobina aplicados em campo têm efeito preventivo e curativo para controle da ferrugem do álamo. Os tratamentos com acibenzolar-S-methyl, amônio quartenário e mancozebe, na forma e dosagem utilizadas nos experimentos, não foram eficientes no controle da ferrugem do álamo.

A desfolha é diretamente proporcional à severidade da ferrugem, com o coeficiente de determinação $\left(\mathrm{R}^{2}=0,69\right)$.

\section{REFERÊNCIAS}

AMORIM, L. Avaliação de doenças. In: BERGAMIN, A. F.; KIMATI, H.; AMORIN, L. (Eds.). Manual de fitopatologia: princípios e conceitos. 3. ed. São Paulo: Ceres, 1995. v. 1, p. 647-670.

ANDRADE, P. J. M.; ANDRADE, D. F. A. A ferrugem asiática - uma ameaça a sojicultura brasileira. Circular Técnica, Dourados, n. 11, 2002.

AZEVEDO, L. A. S. Fungicidas protetores: fundamentos para o uso racional. São Paulo: Lasa, 2003.

BARBOSA, J. C.; MENDONÇA, P. L. P. de; BEGLIOMINI, E.; TOLEDO, V. J. G. Compatibilidade de opus (epoxiconazole) com os adubos foliares da basf em relação ao controle da ferrugem do cafeeiro Hemileia vastatrix Berk e Br. In: CONGRESSO BRASILEIRO DE PESQUISAS CAFEEIRAS, 24., 1998, Poços de Caldas. Anais... Rio de Janeiro: Instituto Brasileiro do Café, 1998.

CAMPBELL, C. L.; MADDEN, L. V. Introduction to plant disease epidemiology. New York: J. Wiley \& Sons, 1990. $655 \mathrm{p}$.

CHASTAGNER, G. A. Poplar diseases. JONES, R. K.; BENSON, D. M. (Eds.). In: Diseases of woody ornamentals and trees in nurseries. Saint. Paul: APS, 2001. p. 308-309. 
FORCELINI, C. A. Fungicidas inibidores da síntese de esteróis. I - Triazoles. In: LUZ, W. C. (Ed.). Revisão anual de patologia de plantas. Passo Fundo: Pe. Berthier, 1994. v. 2, p. 335-356.

FORCELINI, C. A. A ferrugem pode ser manejada. Porto Alegre: Atualidades Agrícolas, 2003. v. 3. p. 8-11.

GHINI, R.; KIMATI, H. Resistência de fungos a fungicidas. 2. ed. Jaguariúna: EMBRAPA Meio Ambiente, 2002. $78 \mathrm{p}$.

GIORCELLI, A.; VIETTO, L. Valutatazione delléfficacia di alcunio fungicidi versu le ruggini del pioppo. Informatore Fitopatológico, Bologna, n. 45, p. 59-62, 1995. (Abstract).

GODOY, C. V.; CANTERI, M. G. Efeitos protetor, curativo e erradicante de fungicidas no controle da ferrugem da soja causada por Phakopsora pachyrhizi, em casa de vegetação. Fitopatologia Brasileira, Brasília, DF, n. 29, p. 97-101, 2004.

KIMATI, H. Controle químico. In: BERGAMIN FILHO, A., KIMATI, H.; AMORIM, L. (Eds.) Manual de fitopatologia: princípios e conceitos. 3. ed. São Paulo: Agronômica Ceres, 1995. v. 1. .p. 761-785.

MARTINELLI, J. A.; FEDERIZZI, L. C.; BENNEDETTI, A. C. Redução do rendimento de grãos de aveia em função da severidade da ferrugem da folha. Summa Phytopathologica, Piracicaba, v. 20, p. 116-118, 1994.

MATIELlO, J. B.; ALMEIDA, S. R.; FERREIRA, R. A. Comparação de fungicidas sistêmicos no controle da ferrugem do cafeeiro sob condição de alta infecção. In: CONGRESSO BRASILEIRO DE PESQUISAS CAFEEIRAS, 21., 1995, Caxambu. Resumos... Caxambu: PROCAFE, 1995. p. 21-22.

MAY-DE MIO, L. L.; AMORIM, L. Doenças do álamo. In: SEMINÁRIO DE ATUALIDADES EM PROTEÇÃO FLORESTAL, 2000, Curitiba. Anais... Curitiba: FUPEF, 2000. p. 139-153.

MAY-DE MIO, L. L.; AMORIM, L. Influência da temperatura e do molhamento foliar nos componentes monocíclicos da ferrugem do álamo. Fitopatologia Brasileira, Brasília, DF, n. 26, p. 232. 2001. (Resumo).

MAY-DE MIO, L. L.; AMORIM, L.; SCHUTA, L. R. Suscetibilidade de clones de álamo à ferrugem no viveiro, eficiência de fungicidas e avaliação de danos. Summa Phytopathologica, Piracicaba, v. 28, n. 1, p. $46-51,2002$.

McCRACKEN, F. I.; SCHIPPER, A. L.; WIDIN, K. D. Observation on occurrence of cottonwood leaf rust in central United States. European Journal of Forest Pathology, Berlin, n. 14, p. 226-233, 1984.

MOLTZAN, B. D. Melampsora feaf rust of Populus: its occurrence, natural distribution and a standardized scale for assessing infection types. (M. Sc. Theses). Fargo, USA. University of North Dakota, 1991.

NEWCOMBE, G.; CHASTAGNER, G. A. A leaf rust epidemic of hybrid poplar along the lower Columbia River caused by Melampsora medusae. Plant Disease, Saint Paul, n. 77, p. 528-531, 1993.

NEWCOMBE, G.; BRADSHAW JÚNIOR, H. D.; CHASTAGNER, G. A.; STETTLER, R. F. The major gene for resistance to Melampsora medusae f.sp. deltoidae in a hybrid poplar pedigree. Phytopathology, Saint Paul, n. 86, p. 87-94. 1996.

NOVARTIS. The plant activator; nature created the concept. Basiléia, 1997. 35 p.

NOWACKI, M. J.; FONTOURA, O. S. Alguns aspectos fitossanitários da silvicultura no estado do Paraná. In: CONGRESSO FLORESTAL BRASILEIRO 1., 1968, Curitiba. Anais... Curitiba: Instituo Forestal do Paraná, 1968. p. 315 -316.

PANDEY, P. C.; SINGH, A.; KARNATAK, D. C.; BHARTARI, B. K. Melampsora larici-populina on poplars in India and its control in nursery. The Indian Forester, Dehra Dun, n. 122, p. 1062-1067, 1996. 
REIS, E. M. Importância do controle de doenças dos cereais de inverno. Correio Agrícola, São Paulo, n. 1, p. 24-27, 1998.

ROCHA, M. R.; CASTRO, R. M.; PINA, R. C.; MARTINI, A. L. Efeito do acibenzolar-s-methyl (Benzothiadiazole), como indutor de resistência sistêmica em soja (Glycine max cv. ftcristalina), sobre Heterodera glycines. Pesquisa Agropecuária Tropical, Goiânia, v. 30, n. 2, p. 35-38 jul. /dez., 2000.

SCHIPPER, A. L.; DAWSON, D. H. Poplar leaf rust - A problem in maximum wood fiber production. Plant Disease Repórter, Washington, DC, n. 58, p. 721-723, 1974.

SOARES, R. M.; RUBIN, S. A. L; WIELEWICKI, A. P.; OZELAME, J. G. Fungicidas no controle da ferrugem asiática (Phakopsora pachyrhizi) e produtividade da soja. Ciência Rural, Santa Maria, v. 34, n. 4, p. 1245-1247, jul-ago, 2004.

SPIERS, A. G. Species of Melampsora infecting conifers in New Zealand. Plant Disease Reporter, Washington, DC, n. 59, p. 486-488, 1975.

STEENACHERS, J.; STEENACHERS, M.; STEENACHERS, V. Maladies des peupliers Consequences sur la croissance et la qualite du bois. Les cahiers techniques de l'objetif 1. Bulletin trimestriel, Hainaut, n. 1, p. 4-20, 1995.

TÖFOLI, J. G.; DOMINGUES, R. J.; FERRERIRA, M. R.; GARCIA JÚNIOR, O. Ação de acibenzolars-methyl isolado e em mistura com fungicidas no controle da requeima da batata. Horticultura Brasileira, Brasília, DF, v. 23, n. 3, p. 749-753, jul-set., 2005.

VIÉGAS, A. P. Alguns fungos do Brasil IV. Uredinales, Bragantia, n.5, p. 6-7, 1945.

WALKER, J. Melampsora medusae. Kew: Commonwealth Mycological Institute, 1975. 2 p. (CMI Descriptions of Patogenic Fungi and Bacteria, n. 480).

WIDIN, K. D.; SCHIPPER JÚNIOR, A. L. Epidemiology and impact of Melampsora medusae leaf rust on hybrid poplars. In: Intensive plantation culture - five year's research. Saint. Paul: USDA. Forest Service, 1976. p. 63-74. (General Technical. Report NC-21). 